\title{
Root canal morphology of South Asian Indian maxillary molar teeth
}

\author{
Shishir Singh ${ }^{1}$, Mansing Pawar ${ }^{1}$
}

Correspondence: Dr. Shishir Singh,

'Department of Conservative Dentistry and Endodontics, Government Dental College and Hospital, St. George Hospital compound, D Mello Road, Near

Email:drshishirs@hotmail.com GPO, Fort. Mumbai, Maharashtra, India

\section{ABSTRACT}

Objective: The objective was to study the root canal morphology of South Asian Indian Maxillary molars using a tooth clearing technique. Materials and Methods: Hundred teeth each comprising of first, second, and third molars collected from different dental schools and clinics in India were subjected to standard dye penetration, decalcification and clearing procedure before being studied. Results: The first molar mesiobuccal roots exhibited 69\% Type I, 24\% Type II, 4\% Type IV, $2 \%$ Type V, and 1\% exhibited a Vertuccis Type VIII canal anatomy. In the group with three separate roots the second molar mesiobuccal roots in exhibited $80.6 \%$ Type I, 15.3\% Type II, 2.7\% Type IV, and 1.4\% Type V canal anatomy while the third molars mesiobuccal roots exhibited $57.4 \%$ Type I, 32\% Type II, 2.1\% Type III, $8.5 \%$ Type IV, $1 \%$ had a Type V canal anatomy in the similar group. Conclusion: A varied root canal anatomy was seen in the mesiobuccal root canal of the maxillary molars.

Key words: Clearing, India ink, maxillary molars, morphology, root canal, Vertucci

\section{INTRODUCTION}

The root canal anatomy of human teeth has puzzled the dentist to no end and has been a source of immense research interest. Starting from way back in 1925 when Hess $^{[1]}$ studied the root canal anatomy by injecting Vulcanite resin into the root canals it was Okumura ${ }^{[2]}$ who stressed the advantages of dye injection and clearing of the teeth for studying the morphology and anatomy of root canals and gave a simple root canal classification.

Various techniques such as sectioning, radiography, dye penetration and clearing, posttreatment clinical examination to modern day cone beam computed tomography techniques have been used to study the root canal anatomy. ${ }^{[3-7]}$ Similarly, various classifications for root canal morphology have been suggested by Okumura 1927, Weine et al. and Vertucci. ${ }^{[2,4,5]}$

Starting from the Caucasians to the Africans and Asians root canal anatomy patterns follow a racial characteristic making endodontic treatment more challenging for the practitioners. ${ }^{[8-23]}$ The various root canal anatomies constituting lateral canals, apical deltas, intercanal anastomoses, and canal designs with their complexities itself, provide conducive environments for microorganisms to proliferate causing periapical infections whose successful elimination plays a major role in the outcome of the endodontic treatment. ${ }^{[24]}$ Finally, it becomes the responsibility of the endodontist to rid these canals of microbial biofilms with proper canal and shaping techniques using various medications and irrigants. A thorough knowledge of the root canal anatomy helps achieve this goal successfully. With globalization and the world coming closer people from various countries and races are found settled all over the world. Their dental needs and treatments confirm the fact that having a better picture of the root canal anatomy characteristics race wise will only but facilitate a more predictable outcome of the treatment.

How to cite this article: Singh S, Pawar M. Root canal morphology of South Asian Indian maxillary molar teeth. Eur J Dent 2015;9:133-44. 
The aim of this research was to study the following: (i) Number of roots and their morphology; (ii) number of root canals per tooth; (iii) root canal configuration in each root using Vertuccis classification, with additional modifications; (iv) presence and location of lateral canals and intercanal communications. This study is one of its first on the morphology of maxillary first, second, and third molars together in the Indian sample using the dye penetration and clearing technique.

\section{MATERIALS AND METHODS}

Three hundred permanent maxillary extracted molars constituting 100 maxillary first, second, and third molars with mature apices from indigenous South Asian Indians of varying age and sex were collected from different dental schools and dental clinics in India. The sample teeth were washed under tap water for 30 minutes and immersed in $2.5 \%$ sodium hypochlorite (Mumbai Healthcare Industries,India) for 30 minutes to remove adherent soft tissue. The adherent soft tissue was physically scraped using a scalpel blade and an ultrasonic scaler cleared calculus or stains after which they were stored in distilled water with Thymol iodide crystals. ${ }^{[5,11,15,17,19-23,53]}$

Standard access preparations were done occlusally using tungsten carbide fissure bur/diamond point in an air turbine handpiece with water irrigation. Any remaining caries was removed at this time. Canal orifices were identified visually or with a DG 16 probe or \#8 K-flex file avoiding any damage/ alteration of the pulpal floor and the root canal anatomy. Preparatory protocols were standardized by carrying out the procedures by a single operator.

The teeth were immersed in $2.5 \%$ sodium hypochlorite (Mumbai Healthcare Industries, India) for $24 \mathrm{~h}$ to dissolve the organic debris and pulp tissue remnants from the root canal systems. After which, the glass bottles containing the teeth and sodium hypochlorite were placed in an ultrasonic bath containing water for $30 \mathrm{~min}$. Subsequently, the teeth were rinsed under running tap water for $2 \mathrm{~h}$ and placed on tissue paper and allowed to dry overnight. Drying is important to aid penetration of ink in the next stage.

A plastic disposable endodontic irrigating syringe gauge 27 needle was used to inject the non waterproof India ink (LOBAL Chemie Laboratory reagants and Fine Chemical, India) into the root canal systems. ${ }^{[19-23]}$ At the same time, a suction tip was placed at the root apex to draw the ink through the root canal system.
The appearance of ink at the apical foramen indicated the end of the process. The teeth were dried overnight again for $12 \mathrm{~h}$.

Thereafter, the teeth were immersed in $10 \%$ nitric acid (Fisher Scientific, Qualigens Fine Chemicals, India) at room temperature for decalcification; the end point of which was determined by taking radiographs at daily intervals. The nitric acid solution was changed daily and agitated frequently, as demineralization occurs at the top of the static acid than the bottom. At the end of decalcification, the teeth were washed in running tap water for $4 \mathrm{~h}$. Excess water was removed and the teeth were left to dry on tissue paper. ${ }^{[19-23]}$

The teeth were dehydrated using ascending concentrations of methanol (Carbimol A.R. Himedia Laboratories, India) at70\%, 95\%, and 100\% consecutively for 1 day each. This meticulous process of dehydration permitted adequate penetration of the clearing agent. After dehydration, the teeth were placed again on tissue paper to dry for $2 \mathrm{~h}$. The teeth were immersed in $2 \%$ methyl salicylate (Oil of Wintergreen, MERCK specialities Pvt. Ltd.) to render them transparent. ${ }^{[19-23]}$

The transparent specimens were then examined by the naked eye as well as a magnifying lens (3X), dipped in methyl salicylate under special halogen lighting so as to improve the coefficient of refraction. The data regarding root and canal morphology of each sample were tabulated based on the number of roots, shape of roots, number of root canals, number of apical foramina, root canal configuration according to Vertuccis classification and number of lateral canals/inter-canal communications/canal anastomoses and compared statistically using the Chi-square test. Photographs of the specimens were taken with a Nikon D 40 camera with a Macro lens (Sigma AF105 mm 1:2.8 EX DG Macro) [Figure 1 and 2].

\section{RESULTS}

The findings of first, second, and the third molars are presented in Table 1.

Of the hundred maxillary first molars all hundred (100\%) had three roots and three root canals. Ninety-three (93\%) teeth had three apical foramen and six $(6 \%)$ teeth had four apical foramen. All hundred teeth $(100 \%)$ had three separate roots; the mesiobuccal roots exhibited sixty-nine $(69 \%)$ with a Vertuccis Type I root canal anatomy, twenty-four $(24 \%)$ had a Type II canal anatomy, four ( $4 \%$ ) had a Type IV canal anatomy, 


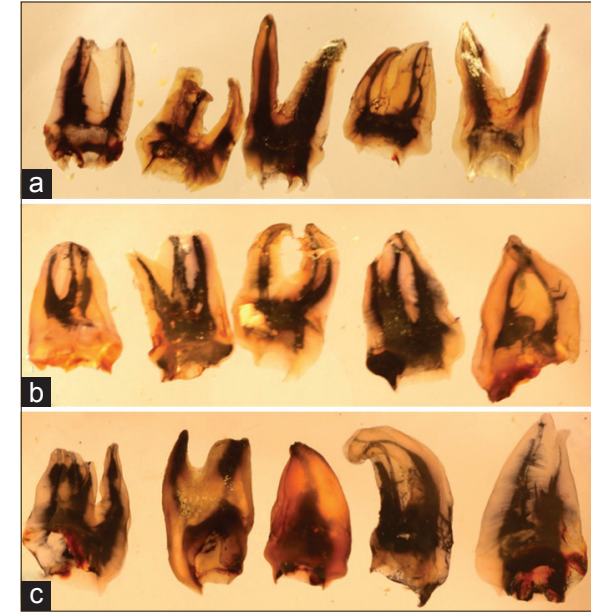

Figure 1: Photographs of injected dye and cleared specimens; maxillary first molars (a); second molars (b) and third molars (c) showing various roots with root canal numbers and canal anatomies

two (2\%) had a Type V canal anatomy and one $(1 \%)$ exhibited a Vertuccis Type VIII canal anatomy. All the hundred $(100 \%)$ distobuccal roots had a Type I root canal anatomy. All the hundred $(100 \%)$ palatal roots had a Type I root canal anatomy. Twenty-eight (28\%) teeth exhibited an MB2 canal. Three mesiobuccal roots $(3 \%)$ had lateral canals with one $(1 \%)$ in the middle third and two (2\%) in the apical thirds. Six $(6 \%)$ teeth showed intercommunications. Twenty-eight (28\%) of maxillary first molars had an MB2 canal.

Of the hundred maxillary second molars, five (5\%) teeth had one root and ninety five (95\%) teeth had three roots. Five (5\%) teeth had one root canal, thirteen (13\%) teeth had two root canals, eighty-two $(82 \%)$ teeth had three root canals. Five $(5 \%)$ teeth had a single apical foramen, twenty-three $(23 \%)$ teeth had two apical foramen, sixty-nine $(69 \%)$ teeth had three apical foramen, and three $(3 \%)$ had four apical foramen.

Seventy-two $(72 \%)$ teeth had three separate roots, twenty-three $(23 \%)$ had two separate roots and five $(5 \%)$ teeth had a single root. In the group with three separate roots, the mesiobuccal roots exhibited fifty-eight $(80.55 \%)$ with a Vertuccis Type I root canal anatomy, eleven (15.3\%) had a Type II canal anatomy, two $(2.7 \%)$ had a Type IV canal anatomy, one $(1.4 \%)$ had a Type $\mathrm{V}$ canal anatomy. All the seventy two $(100 \%)$ distobuccal roots had a Type I root canal anatomy. Seventy $(97.2 \%)$ palatal roots had a Type I root canal anatomy, one $(1.4 \%)$ had a Type III anatomy and one $(1.4 \%)$ palatal root had a Type IV root canal anatomy. In the group with two roots all $23(100 \%)$ had Vertuccis Type I anatomy for the buccal and palatal roots. In the Group with a single root, all $5(100 \%)$ exhibited a type I root canal anatomy.

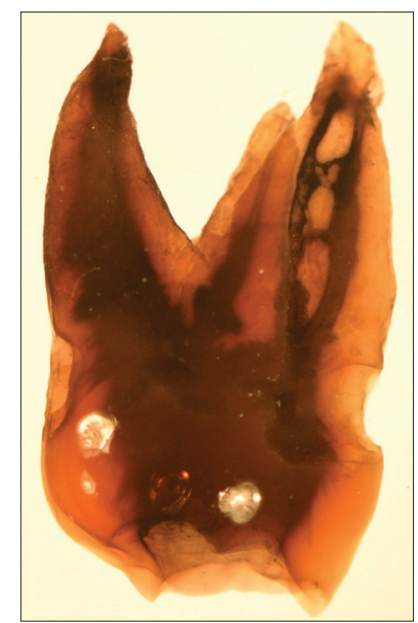

Figure 2: Cleared maxillary first molar showing intercommunications between canals

Six mesiobuccal roots $(6 \%)$ had lateral canals with three $(3 \%)$ in the middle third and three (3\%) in the apical thirds. Six $(6 \%)$ teeth showed intercommunications. Thirteen (18\%) of maxillary second molars had an MB2 canal.

Of thehundred maxillary third molars, twenty (20\%) teeth had one root, thirty-three (33\%) teeth had two roots and forty seven (47\%) teeth had three roots. Nineteen (19\%) teeth had one root canal, thirty-three (33\%) teeth had two root canals, forty-three (43\%) teeth had three root canals, and five (5\%) teeth had four root canals. Twenty $(20 \%)$ teeth had a single apical foramen, thirty-three (33\%) teeth had two apical foramen, forty-three (43\%) teeth had three apical foramen, and four (4\%) teeth had four apical foramen. Forty-seven $(47 \%)$ teeth had three separate roots, thirty-three teeth $(33 \%)$ had two separate roots and twenty $(20 \%)$ teeth had a single conical root. In the group with three separate roots, the mesiobuccal roots exhibited twenty-seven (57.4\%) with a Vertuccis Type I root canal anatomy, fifteen $(32 \%)$ had a Type II canal anatomy, one $(2.1 \%)$ had a Type III canal anatomy and four $(8.5 \%)$ teeth had a Type IV canal anatomy. All the forty-seven $(100 \%)$ distobuccal roots and Palatal roots had a Type I root canal anatomy. In the group with thirty three two roots; the buccal roots showed 31 (94\%) with Vertuccis Type Ianatomy, one (3\%) Type III and one (3\%) Type IV, As for the palatal roots thirty two (97\%) teeth had a Type I anatomy and one (3\%) tooth had a Type IV anatomy. In the Group with a twenty single roots eighteen $(90 \%)$ exhibited a type I root canal anatomy, one (5\%) Type III and one (5\%) exhibited Type V canal anatomy. Four mesiobuccal roots $(4 \%)$ had lateral canals with all four $(4 \%)$ in the apical thirds. Two (2\%) teeth showed intercommunications. Nineteen $(40.5 \%)$ of maxillary third molars had a MB2 canal. 


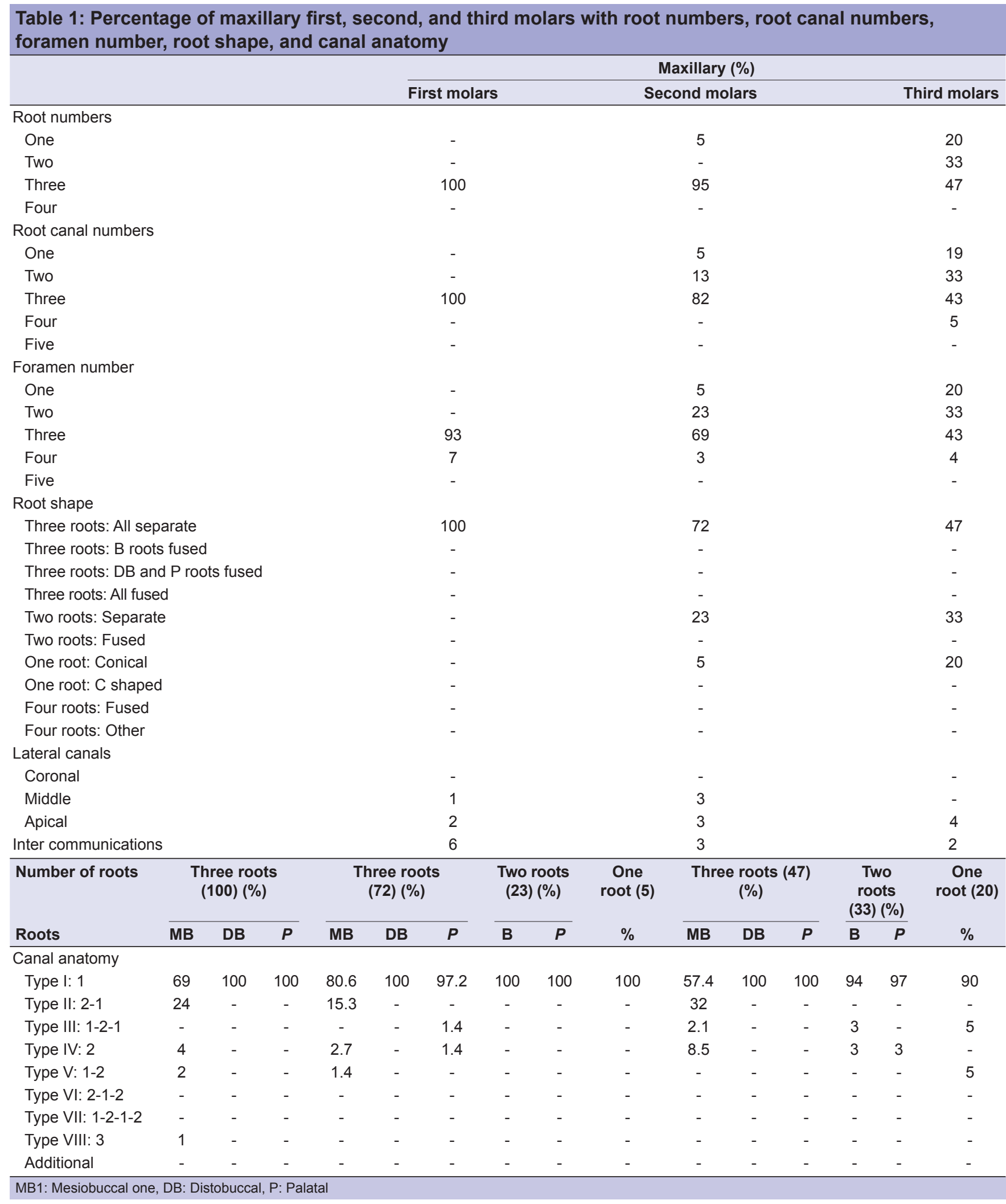

\section{DISCUSSION}

Studies related to root canal anatomy of maxillary first, second, and third molars are summarized in Table 2. The use of the dye penetration and clearing technique as mentioned by Okumura and Robertson et al. with its various advantages has been in use for decades by various researchers 
Singh and Pawar: Morphology of Indian maxillary molars

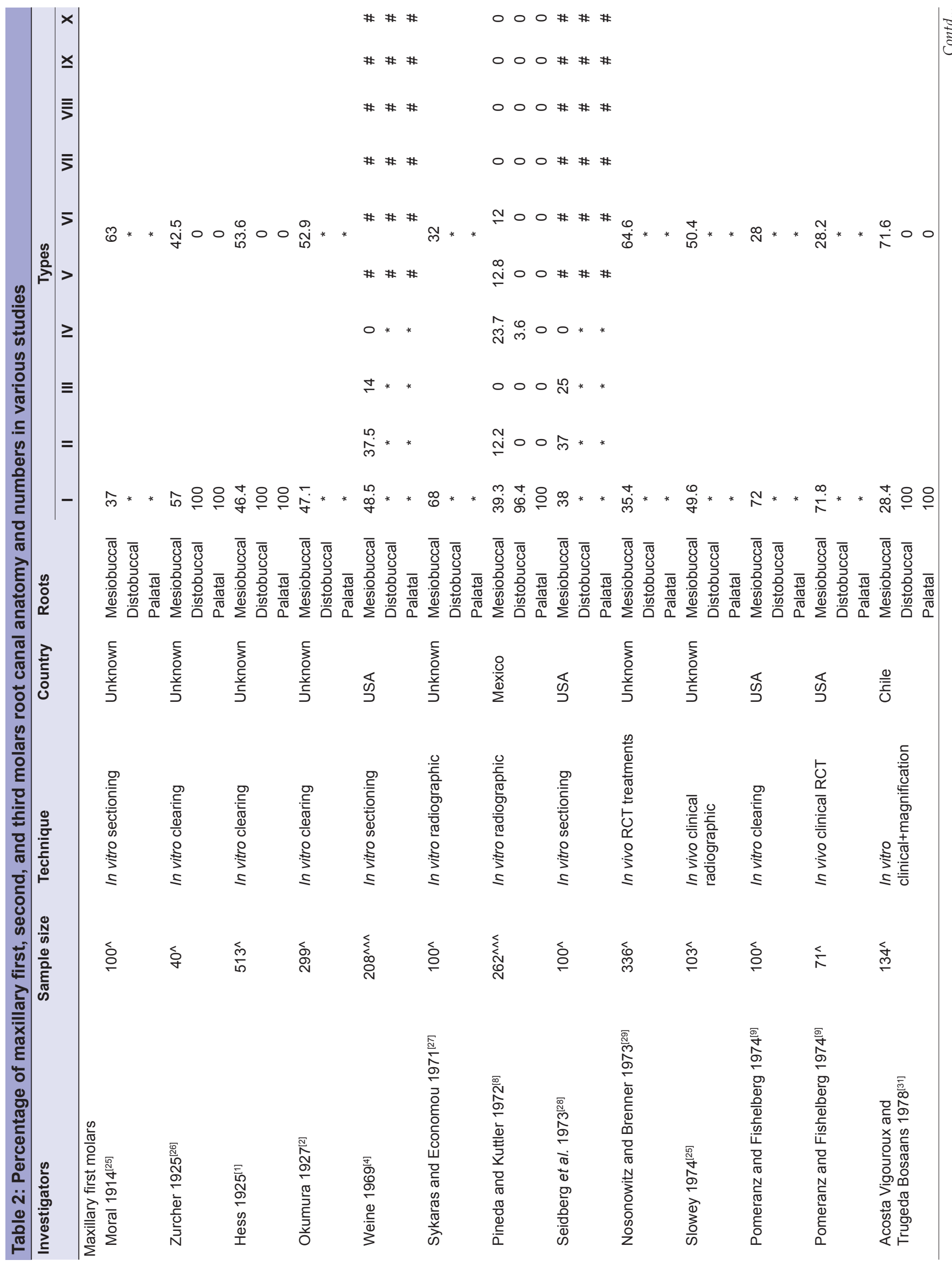




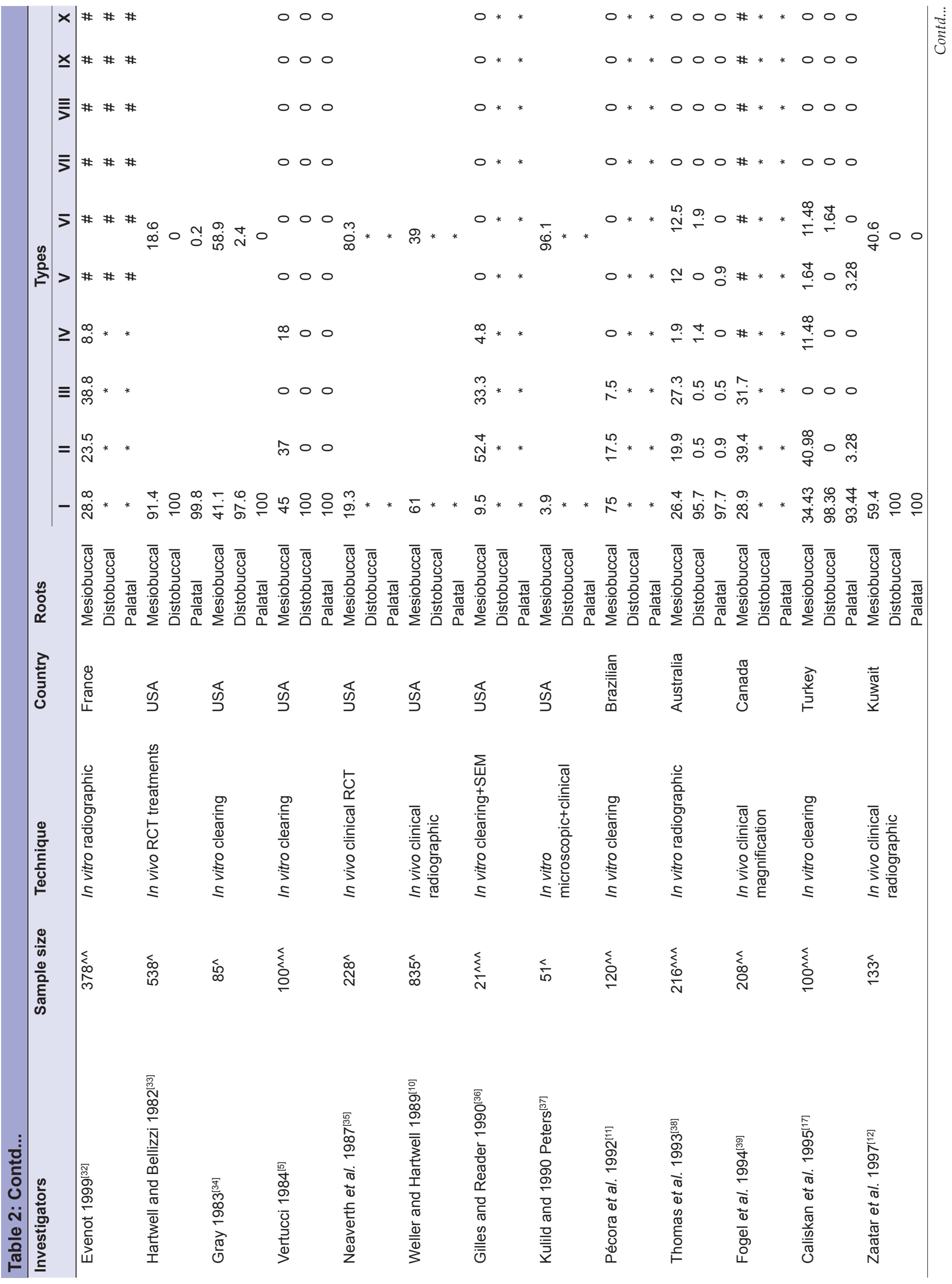


Singh and Pawar: Morphology of Indian maxillary molars

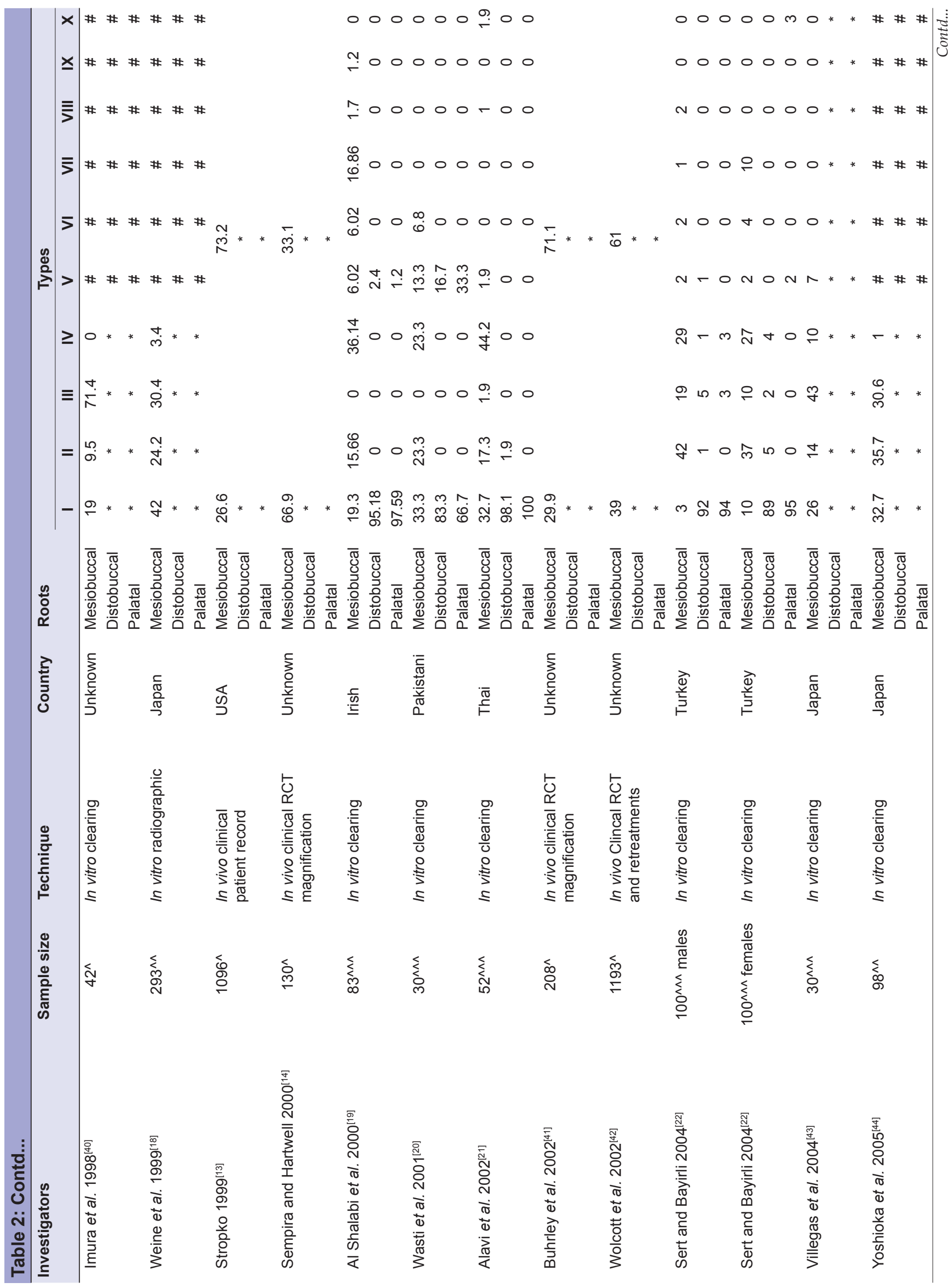




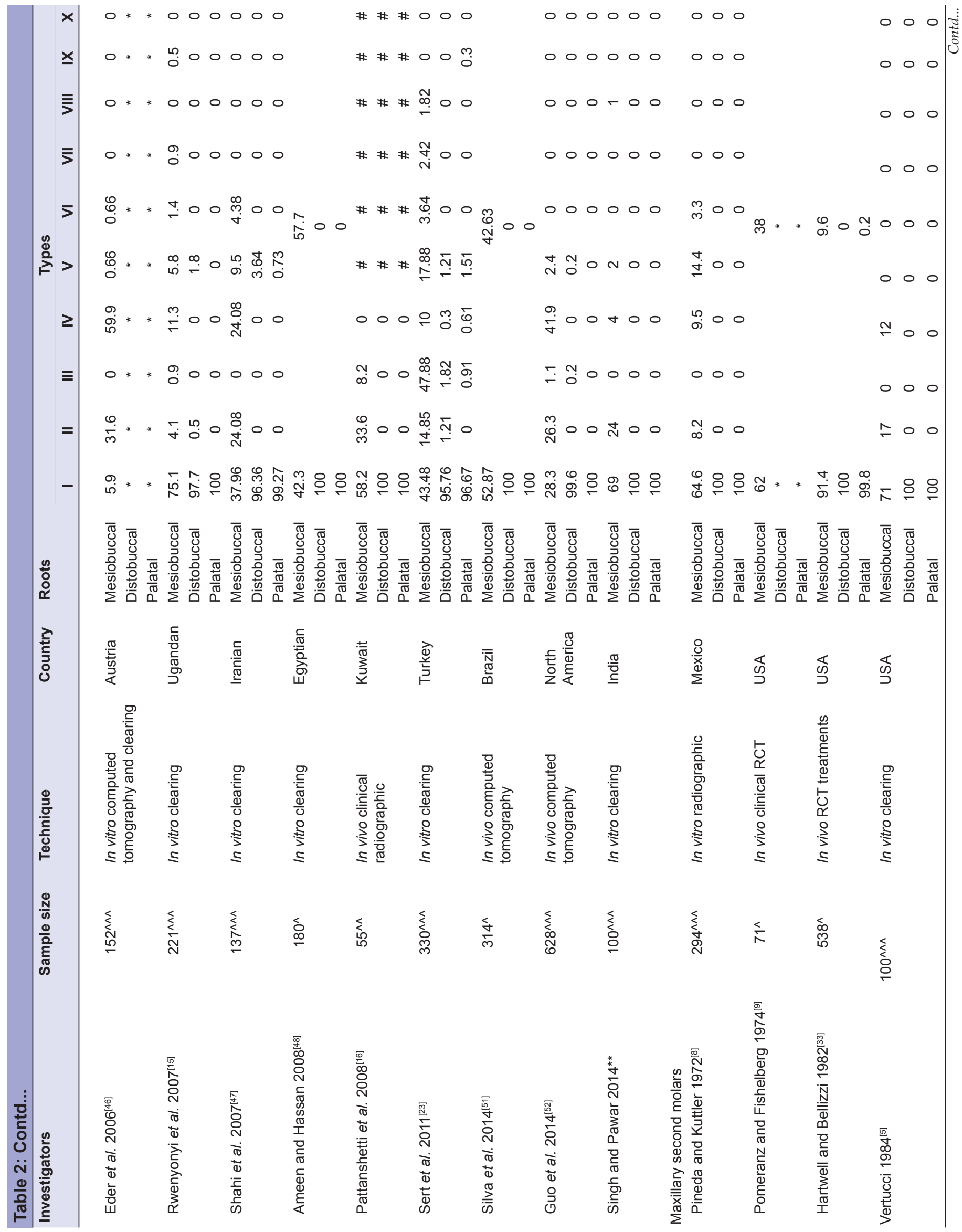


Singh and Pawar: Morphology of Indian maxillary molars

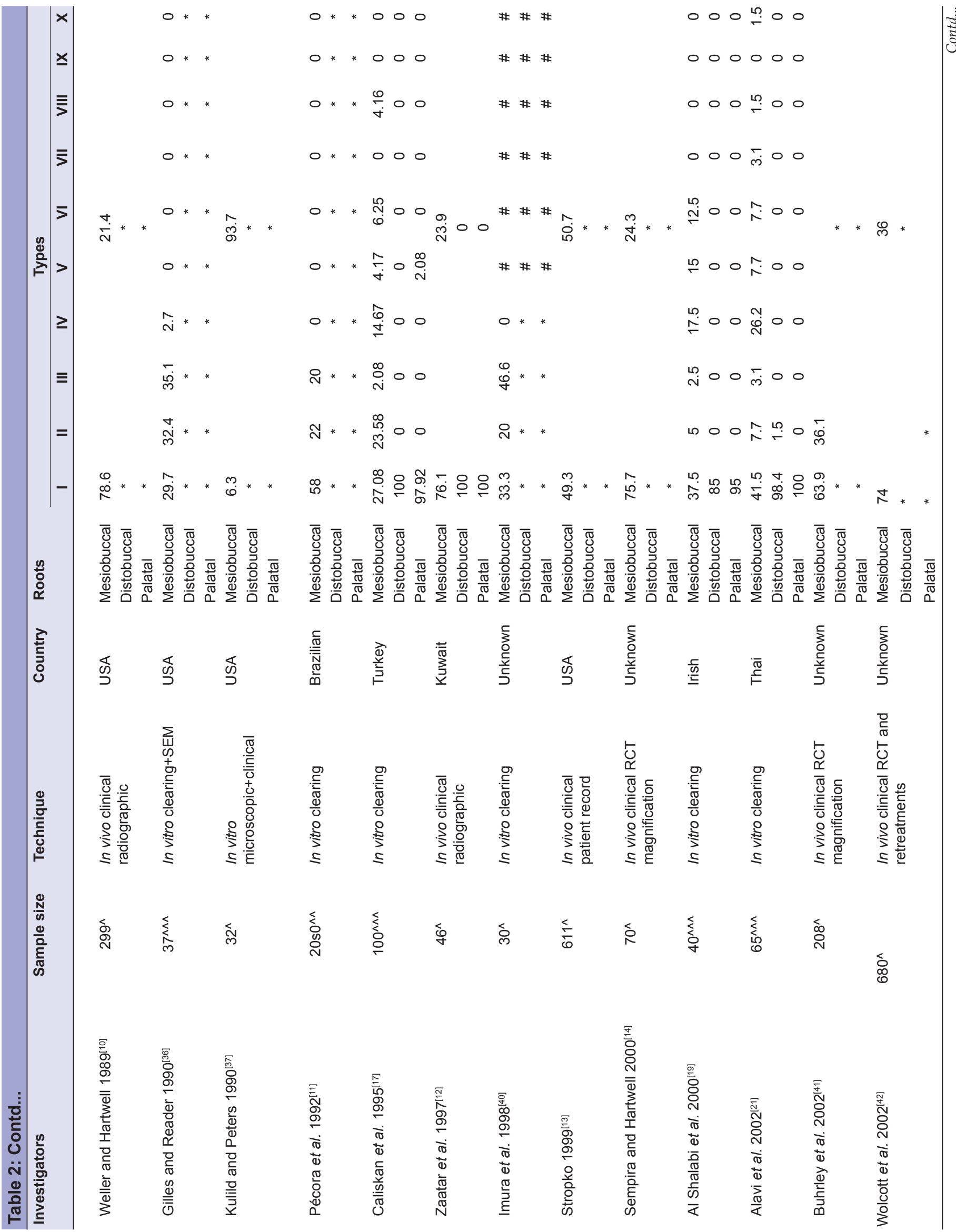




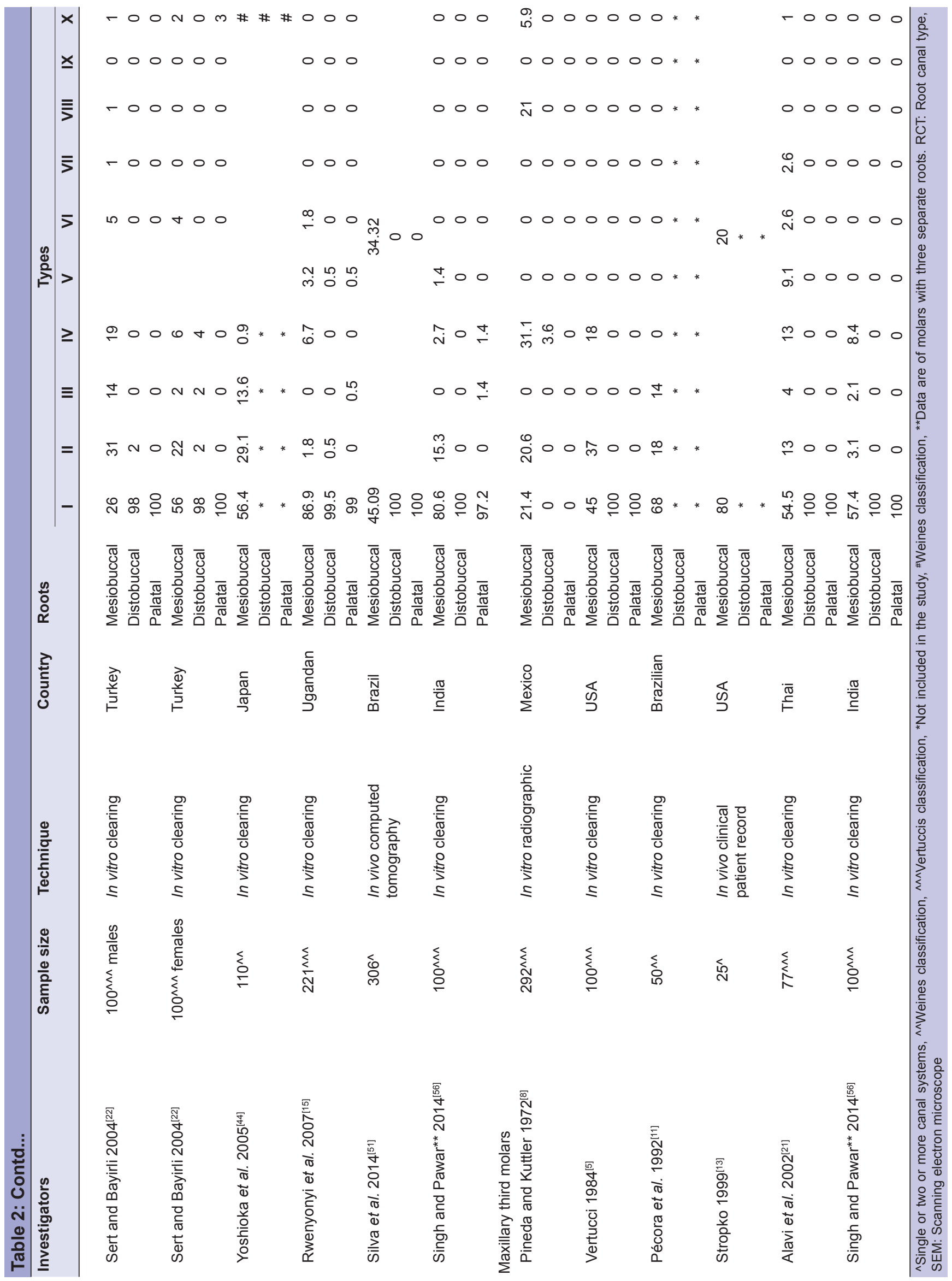


to study the root canal anatomy of human teeth world wide. ${ }^{[2,53,54]}$

The clearing technique followed in this study resulted in very clear specimens, allowing good visualization and photography of the canal anatomy. The incidence of lateral canals in the Indian population was not significant when compared with similar studies done on other racial populations suggesting this could be a racial characteristic. Observations were made by examining the specimens with a magnifying glass under good lighting to study their root canal morphology. The universally accepted Vertucci's classification was used to study the root canal anatomy. ${ }^{[5]}$

Researchers worldwide have been studying the root canal anatomy of the maxillary molars for a century now. They have used various in vitro techniques such as sectioning, clearing, radiographic, microscopic, clinical, or a combination of two or more. The in vivo techniques constitute clinical, radiographic, post treatment records studies, which are less in number when compared with the in vitro techniques with the dye penetration and clearing being used most often setting it as the gold standard. ${ }^{[3,30]}$ The advantages of this technique have been discussed by Okumura, ${ }^{[2]}$ Robertson et al., ${ }^{[53,54]}$ Omer et al. ${ }^{[55]}$ and has been used in a recently published study by Singh and Pawar. ${ }^{[56]}$ Though the modern CBCT techniques by Neelkantan et al., Nur et al. and Altunsoy et al. and other researchers. ${ }^{[6,45,49,50,57,58]}$ as well as the combination of alternating image reformatting techniques in micro-computed tomography involving two-dimensional minimum intensity projection and 3-dimensional volume rendering reconstruction images have been discussed, ${ }_{i]}^{[7]}$ the time tested clearing technique was used in this study. There is no doubt that the dye penetration and clearing technique helps in a better visualization and understanding of the root canal anatomy adding more value in endodontic teaching. Not all studies mentioned the racial characteristics of the sample nor have they used a standardized root canal classification system. While the earlier studies have mentioned a simple classification, a few have followed the Weines system with the detailed and more sensitive Vertuccis system being used in the later studies ${ }^{[5]}$ It is noteworthy that many researchers have only studied anatomy of the mesiobuccal root of the maxillary molar, perhaps in the quest of the second mesiobuccal canal. In this study $28 \%$ of first molars of, $18 \%$ of second molars and $40.5 \%$ third molars exhibited MB2 canals which is an interesting finding for the clinician. The results of various studies show that the incidence of an extra canal in the mesiobuccal root of Indians is much less than the Europeans ${ }^{[17,23,31,36,46,47]}$ and Far eastern Thai ${ }^{[21]}$ and Japanese races ${ }^{[18,39]}$ and is similar to the Brazilians, ${ }^{[11]}$ Mexicans, ${ }^{[8]}$ African Ugandans, ${ }^{[15]}$ and the Kuwaitis ${ }^{[12,16]}$ which can be considered a racial characteristic. This observation is of immense value during the endodontic treatment of Indian molars.

It is interesting to note the incidence of MB2 canals in the maxillary molars typical to Indian teeth as compared to other races. This could be a racial characteristic as their incidence is higher in the Caucasian, European and Far eastern Thai and Japanese races. Our findings suggest that the root canal morphology of Indian molar teeth is similar to the Mexicans, Brazilians, African Ugandans, and the Kuwaitis, which can be considered a racial characteristic. Further research on interracial anatomical characteristics from different geographical locations would be beneficial for a comparative study.

\section{ACKNOWLEDGMENTS}

This original research work is part of $\mathrm{PhD}$ dissertation requirement of Maharashtra University of Health Sciences. The authors appreciate the help given by Dr. Gaurav Kulkarni for processing the images.

\section{REFERENCES}

1. Hess W. The Anatomy of the Root Canals of the Teeth of the Permanent and Deciduous Dentition. New York: William Wood and Co.; 1925. p. 1-39.

2. Okumura T. Anatomy of the root canals. J Am Dent Assoc 1927;14:632-6.

3. Weine FS, Pasiewicz RA, Rice RT. Canal configuration of the mandibular second molar using a clinically oriented in vitro method. J Endod 1988;14:207-13.

4. Weine FS, Healey HJ, Gerstein H, Evanson L. Canal configuration in the mesiobuccal root of the maxillary first molar and its endodontic significance. Oral Surg Oral Med Oral Pathol 1969;28:419-25.

5. Vertucci FJ. Root canal anatomy of the human permanent teeth. Oral Surg Oral Med Oral Pathol 1984;58:589-99.

6. Neelakantan P, Subbarao C, Subbarao CV. Comparative evaluation of modified canal staining and clearing technique, cone-beam computed tomography, peripheral quantitative computed tomography, spiral computed tomography, and plain and contrast medium-enhanced digital radiography in studying root canal morphology. J Endod 2010;36:1547-51.

7. Lee KW, Kim Y, Perinpanayagam H, Lee JK, Yoo YJ, Lim SM, et al. Comparison of alternative image reformatting techniques in micro-computed tomography and tooth clearing for detailed canal morphology. J Endod 2014;40:417-22.

8. Pineda F, Kuttler Y. Mesiodistal and buccolingual roentgenographic investigation of 7,275 root canals. Oral Surg Oral Med Oral Pathol 1972;33:101-10.

9. Pomeranz HH, Fishelberg G. The secondary mesiobuccal canal of maxillary molars. J Am Dent Assoc 1974;88:119-24.

10. Weller RN, Hartwell GR. The impact of improved access and searching techniques on detection of the mesiolingual canal in maxillary molars. J Endod 1989;15:82-3.

11. Pécora JD, Woelfel JB, Sousa Neto MD, Issa EP. Morphologic study of the maxillary molars. Part II: Internal anatomy. Braz Dent J 1992;3:53-7. 
12. Zaatar EI, al-Kandari AM, Alhomaidah S, al-Yasin IM. Frequency of endodontic treatment in Kuwait: Radiographic evaluation of 846 endodontically treated teeth. J Endod 1997;23:453-6.

13. Stropko JJ. Canal morphology of maxillary molars: Clinical observations of canal configurations. J Endod 1999;25:446-50.

14. Sempira HN, Hartwell GR. Frequency of second mesiobuccal canals in maxillary molars as determined by use of an operating microscope: A clinical study. J Endod 2000;26:673-4.

15. Rwenyonyi CM, Kutesa AM, Muwazi LM, Buwembo W. Root and canal morphology of maxillary first and second permanent molar teeth in a Ugandan population. Int Endod J 2007;40:679-83.

16. Pattanshetti N, Gaidhane M, Al Kandari AM. Root and canal morphology of the mesiobuccal and distal roots of permanent first molars in a Kuwait population - a clinical study. Int Endod J 2008;41:755-62.

17. Caliskan MK, Pehlivan Y, Sepetçioglu F, Türkün M, Tuncer SS. Root canal morphology of human permanent teeth in a Turkish population. J Endod 1995;21:200-4.

18. Weine FS, Hayami S, Hata G, Toda T. Canal configuration of the mesiobuccal root of the maxillary first molar of a Japanese sub-population. Int Endod J 1999;32:79-87.

19. Al Shalabi RM, Omer OE, Glennon J, Jennings M, Claffey NM. Root canal anatomy of maxillary first and second permanent molars. Int Endod J 2000;33:405-14.

20. Wasti F, Shearer AC, Wilson NH. Root canal systems of the mandibular and maxillary first permanent molar teeth of south Asian Pakistanis. Int Endod J 2001;34:263-6.

21. Alavi AM, Opasanon A, Ng YL, Gulabivala K. Root and canal morphology of Thai maxillary molars. Int Endod J 2002;35:478-85.

22. Sert S, Bayirli GS. Evaluation of the root canal configurations of the mandibular and maxillary permanent teeth by gender in the Turkish population. J Endod 2004;30:391-8.

23. Sert S, Sahinkesen G, Topçu FT, Eroglu SE, Oktay EA. Root canal configurations of third molar teeth. A comparison with first and second molars in the Turkish population. Aust Endod J 2011;37:109-17.

24. Vertucci FJ. Root canal morphology and its relationship to endodontic procedures. Endod Topics 2005;10:3-29.

25. Moral H. 'Veber Pulpaaüsgusse.' Deutsche Monatsschrift für Zahnheilkunde 1914;32:617-624.

26. Zurcher E. The Anatomy of the Root Canals of the Teeth of the Deciduous Dentition and of the First Permanent Molars, Part 2. New York: William Wood and Co.; 1925.

27. Sykaras S, Economou P. Root canal morphology of the mesiobuccal root of the maxillary first molar. Odontostomatol Proodos 1970;24:99-108.

28. Seidberg BH, Altman M, Guttuso J, Suson M. Frequency of two mesiobuccal root canals in maxillary permanent first molars. J Am Dent Assoc 1973;87:852-6.

29. Nosonowitz DM, Brenner MR. The major canals of the mesiobuccal root of the maxillary $1^{\text {st }}$ and $2^{\text {nd }}$ molars. N Y J Dent 1973;43:12-5.

30. Slowey RR. Radiographic aids in the detection of extra root canals. Oral Surg Oral Med Oral Pathol 1974;37:762-72.

31. Acosta Vigouroux SA, Trugeda Bosaans SA. Anatomy of the pulp chamber floor of the permanent maxillary first molar. J Endod 1978;4:214-9.

32. Evenot M. Contribution a la connaisance des systemes endodontiques complexes la racine mesio vestibulaire de la premiere molaire maxillaire, approche, instrumentale, Clinique at pedagogique. PhD thesis. Academie de paris. Universite Rene Descartes, Paris, France; p. 347.

33. Hartwell G, Bellizzi R. Clinical investigation of in vivo endodontically treated mandibular and maxillary molars. J Endod 1982;8:555-7.

34. Gray R. The maxillary first molar. In: Bjorndal AM, Skidmore AE, editors. Anatomy and Morphology of Permanent Teeth. Iowa City: University of Iowa College of Dentistry; 1983.

35. Neaverth EJ, Kotler LM, Kaltenbach RF. Clinical investigation (in vivo) of endodontically treated maxillary first molars. J Endod 1987;13:506-12.

36. Gilles J, Reader A. An SEM investigation of the mesiolingual canal in human maxillary first and second molars. Oral Surg Oral Med Oral Pathol 1990;70:638-43.

37. Kulild JC, Peters DD. Incidence and configuration of canal systems in the mesiobuccal root of maxillary first and second molars. J Endod 1990;16:311-7.

38. Thomas RP, Moule AJ, Bryant R. Root canal morphology of maxillary permanent first molar teeth at various ages. Int Endod J 1993;26:257-67.
39. Fogel HM, Peikoff MD, Christie WH. Canal configuration in the mesiobuccal root of the maxillary first molar: A clinical study. J Endod 1994;20:135-7.

40. Imura N, Hata GI, Toda T, Otani SM, Fagundes MI. Two canals in mesiobuccal roots of maxillary molars. Int Endod J 1998;31:410-4.

41. Buhrley LJ, Barrows MJ, BeGole EA, Wenckus CS. Effect of magnification on locating the MB2 canal in maxillary molars. J Endod 2002;28:324-7.

42. Wolcott J, Ishley D, Kennedy W, Johnson S, Minnich S. Clinical investigation of second mesiobuccal canals in endodontically treated and retreated maxillary molars. J Endod 2002;28:477-9.

43. Villegas JC, Yoshioka T, Kobayashi C, Suda H. Frequency of transverse anastomoses with and without apical communication in Japanese population teeth. Aust Endod J 2004;30:50-2.

44. Yoshioka T, Kikuchi I, Fukumoto Y, Kobayashi C, Suda H. Detection of the second mesiobuccal canal in mesiobuccal roots of maxillary molar teeth ex vivo. Int Endod J 2005;38:124-8.

45. Wu DM, Wu YN, Guo W, Sameer S. Accuracy of direct digital radiography in the study of the root canal type. Dentomaxillofac Radiol 2006;35:263-5.

46. Eder A, Kantor M, Nell A, Moser T, Gahleitner A, Schedle A, et al. Root canal system in the mesiobuccal root of the maxillary first molar: An in vitro comparison study of computed tomography and histology. Dentomaxillofac Radiol 2006;35:175-7.

47. Shahi S, Yavari HR, Rahimi S, Ahmadi A. Root canal configuration of maxillary first permanent molars in an Iranian population. J Dent Res Dent Clin Dent Prospects 2007;1:1-5.

48. Ameen RM, Hassan RM. A study on the external and internal root anatomy of Egyptian maxillary first permanent molar. Cairo Dent J 2008;24:29-36.

49. Degerness RA, Bowles WR. Dimension, anatomy and morphology of the mesiobuccal root canal system in maxillary molars. J Endod 2010;36:985-9.

50. Yu X, Guo B, Li KZ, Zhang R, Tian YY, Wang H, et al. Cone-beam computed tomography study of root and canal morphology of mandibular premolars in a western Chinese population. BMC Med Imaging 2012;12:18.

51. Silva EJ, Nejaim Y, Silva AI, Haiter-Neto F, Zaia AA, Cohenca N. Evaluation of root canal configuration of maxillary molars in a Brazilian population using cone-beam computed tomographic imaging: An in vivo study. J Endod 2014;40:173-6.

52. Guo J, Vahidnia A, Sedghizadeh P, Enciso R. Evaluation of root and canal morphology of maxillary permanent first molars in a North American population by cone-beam computed tomography. J Endod 2014;40:635-9.

53. Robertson D, Leeb IJ, McKee M, Brewer E. A clearing technique for the study of root canal systems. J Endod 1980;6:421-4.

54. Robertson DC, Leeb IJ. The evaluation of a transparent tooth model system for the evaluation of endodontically filled teeth. J Endod 1982;8:317-21.

55. Omer OE, Al Shalabi RM, Jennings M, Glennon J, Claffey NM. A comparison between clearing and radiographic techniques in the study of the root-canal anatomy of maxillary first and second molars. Int Endod J 2004;37:291-6.

56. Singh S, Pawar M. Root canal morphology of South asian Indian mandibular premolar teeth. J Endod 2014;40:1338-41.

57. Nur BG, Ok E, Altunsoy M, Aglarci OS, Colak M, Gungor E. Evaluation of the root and canal morphology of mandibular permanent molars in a south-eastern Turkish population using cone-beam computed tomography. Eur J Dent 2014;8:154-9.

58. Altunsoy M, Ok E, Nur BG, Aglarci OS, Gungor E, Colak M. A cone-beam computed tomography study of the root canal morphology of anterior teeth in a Turkish population. Eur J Dent 2014;8:302-6.

\begin{tabular}{|l|l|}
\hline \multicolumn{2}{|c|}{ Access this article online } \\
\hline Quick Response Code: & $\begin{array}{l}\text { Website: } \\
\text { www.eurjdent.com }\end{array}$ \\
\cline { 2 - 3 } & $\begin{array}{l}\text { Source of Support: TInternal funding } \\
\text { from Bharath University. } \\
\text { Conflict of Interest: None declared }\end{array}$ \\
\end{tabular}

